\title{
"SOU VERDE DE VERDADE": ESTRATÉGIAS MERCADOLÓGICAS DA ECONOMIA CRIATIVA PARA SUPERAR A DESCONFIANÇA DO CONSUMIDOR
}

\author{
Luana Batista Rodrigues ${ }^{1}$ \\ Francisco Edson Rodrigues da Silva ${ }^{2}$ \\ Cláudia Buhamra Abreu Romero ${ }^{3}$
}

\section{RESUMO}

Objetivo: Esta pesquisa tem por objetivo identificar as estratégias de marketing utilizadas por negócios verdes do ra mo de cosmética natural artesanal para superar a desconfiança do consumidor face às práticas de greenwashing das chamadas empresas pseudoverdes.

Referencial teórico: Este artigo foi fundamentado principalmente nos estudos de Danciu (2015), Perez, Garzon e Ibara (2016) e Jog e Singhal (2019). As estratégias de mercado por eles levantadas foram consolidadas em um modelo a ser adotado pelos negócios verdes.

Método: Trata-se de uma pesquisa qualitativa, estruturada a partir de um estudo de casos múltiplos de três n egócios.

Resultados e conclusão: Os resultados a pontam que o foco na criação de produtos sustentá veis e na promoção aparece como estra tégia -chave para esses negócios no combate à desconfiança do consumidor, construindo, a ssim, uma rela çã o próxima com ele, pautada na confiabilidade e na transparência.

Implicações da pesquisa: Esse estudo se faz relevante pelo modelo de estratégias mercadológicas utilizadas pelas empreendedoras, podendo ser replica do por outros negócios que necessitem conquistar a confiança do consumidor com relação a os seus produtos naturais.

Originalidade/valor: $\mathrm{O}$ artigo a presenta um modelo de estra tégias que auxiliam na consolidação de negócios verdes no mercado, o que representa um avanço teórico nesse segmento.

Palavras-chave: Empresas verdes. Greenwashing. Estratégias de marketing. Economia criativa. Cosmética natural artesanal.

RGSA adota a Licença de Atribuição CC BY do Creative Commons (https://creativecommons.org/licenses/by/4.0/).

\footnotetext{
${ }^{1}$ Mestre em Administração e Controladoria pelo Programa de Pós-Graduação em Administração e Controladoria Universida de Federal do Ceará, Ceará (Bra sil). Email: lbrodrigues@ ufc.br Orcid: https://orcid.org/0000-0001-5549-2936

${ }^{2}$ Mestrando em Administração e Controladoria pelo Programa de Pós-Graduação em Administração e Controladoria Universida de Federal do Ceará, Ceará (Brasil). Email: fedsonrsilva @ hotmail.com Orcid: https://orcid.org/0000-0003-0572$\underline{916 X}$
}

${ }^{3}$ Pós-Doutorado em Administração de Marketing pela John Molson School of Business da Concordia Unive rsity (Ca nadá). Professora Titular da Universidade Federal do Ceará, Ceará (Brasil). Email: buhamra@ ufc.br Orcid: https://orcid.org/0000$\underline{0002-5971-7693}$

$$
\begin{array}{|l|l|l|l|l|}
\hline \text { Rev. Gest. Soc. Ambient. } & \text { São Paulo (SP) } & \text { v.15 } & \text { p.01-17 } & \text { e02780|2021. } \\
\hline
\end{array}
$$




\title{
I'M REALLY GREEN! MARKETING STRATEGIES IN THE CREATIVE ECONOMY TO OVERCOME CONSUMER DISTRUST
}

\begin{abstract}
Purpose: This research aims to understand the marketing strategies used by green businesses of natural handmade cosmetics to overcome the consumer distrust of the greenwashing practices of so-called pseudo-green players.
\end{abstract}

Method/design/approach: This is a qualitative research, structured from a multiple case study with three players.

Results and conclusion: The results show that the focus on creating sustainable products and on promotion appear as key strategies for these businesses in combating consumers distrust, thus building a close relationship with them, based on reliability and transparency.

Research implications: This study is relevant for the model of marketing strategies used by the entrepreneurs, which may be replicated by other green players that need to gain consumer confidence in their naturalproducts.

Originality/value: The paper presents a model of strategies that help to consolidate green businesses, which represents a theoretical advance in this segment.

Keywords: Green players. Greenwa shing. Marketing strategies. Creative economy. Handmade natural cosmetics.

\section{INTRODUÇÃO}

As mudanças no contexto socioeconômico mundial têm evidenciado a necessidade de adoção de práticas sustentáveis e ecologicamente corretas, principalmente por parte das organizações. Nesse cenário, destaca-se a economia criativa, um tipo de economia centrada nas artes, na cultura, nas artesanias e saberes locais e em valores como inclusão e diversidade, que têm a sustentabilidade como um de seus pilares. Muitos setores criativos têm oferecido soluções ambientais, econômicas e sociais a partir de atividades como a moda, o artesanato e a cosmética natural artesanal (Conferência das Nações Unidas sobre Comércio e Desenvolvimento [UNCTAD], 2010; Pires \& Albagli, 2012; Vega, 2021).

Esta pesquisa foca no setor de cosmético natural artesanal, que aposta em uma produção livre de insumos danosos ao meio ambiente e à saúde humana, descartando práticas de crueldade animal e priorizando materiais biodegradáveis e reutilizados. $O$ setor conta com a crescente demanda por produtos de cuidados pessoais e a valorização de produtos naturais para esse fim, uma vez que consumidores acreditam que esse tipo de produto traz menos efeitos colaterais que os quimicamente industrializados (Kim \& Chung, 2011; Joshi \& Pawar, 2015; Liobikiene \& Bernatoniene, 2017; Lin, Yang, Hanifah \& Iqbal, 2018; Jog \& Singhal, 2019).

Assim, em um contexto no qual a sustentabilidade aparece como diferencial competitivo, práticas ecologicamente corretas contribuem positivamente com a imagem das empresas, impulsionando seu crescimento e perenidade (Katsikeas, Leonidou \& Zeriti, 2016; Kelleci, 2021). Porém, nem sempre essa imagem é genuína. Com o aumento da disponibilidade de produtos verdes no mercado, cresceu também o que se chama de greenwashing, uma estratégia que consiste em enganar o consumidor sobre práticas ecológicas de uma empresa ou sobre os benefícios ambientais de seus produtos e serviços (Parguel, Benoît-Moreau e Larceneux, 2011; Singhal \& Agrawal, 2021). As empresas que praticam tais ações são chamadas de "pseudoverdes" (Jog \& Singhal, 2019).

Nesse cenário, negócios que de fato incorporam práticas verdes são prejudicados pela perda de confiança do consumidor, que deixa de reconhecer o valor agregado desses produtos. O setor de cosméticos também não passa imune ao greenwashing, o que torna isso um desafio para os negócios verdes produtores de cosméticos naturais se diferenciarem das empresas pseudoverdes e 
vencerem a desconfiança do consumidor sobre a sua autenticidade (Guyader, Ottosson \& Witell, 2017; Lin et al., 2018).

Assim, considerando o desafio exposto, questiona-se: como os negócios verdes do ramo de cosmética natural artesanal, integrantes da economia criativa, conseguem superar a desconfiança do consumidor em face das práticas de greenwashing? Este estudo encontra sua relevância na medida em que os casos apresentam características inéditas, podendo servir de modelo para outras experiências. Além disso, o artigo apresenta um modelo de estratégias que auxiliam na consolidação de negócios verdes no mercado. Particularmente no caso brasileiro, este estudo encontra importância diante do fato de que o país é um dos maiores mercados consumidores de cosméticos do mundo, além de contar com uma rica biodiversidade, o que representa grande potencial de desenvolvimento do mercado de cosméticos naturais (Associação Brasileira da Indústria de Higiene Pessoal, Perfumaria e Cosméticos [ABIHPEC], 2017; Mendes, 2019).

Com o intuito de responder à questão de pesquisa, formulou-se o seguinte objetivo: identificar as estratégias de marketing utilizadas por negócios verdes do ramo de cosmética natural artesanal para superar a desconfiança do consumidor face às práticas de greenwashing das chamadas empresas pseudoverdes. Para a sua consecução, realizou-se uma pesquisa qualitativa, a partir de um estudo de casos múltiplos com três negócios do ramo de cosmético natural artesanal da cidade de Fortaleza (CE), chancelada pela Organização das Nações Unidas para a Educação, a Ciência e a Cultura (UNESCO), em 2019, como Cidade Criativa do design (Prefeitura de Fortaleza, 2019), evidenciando a referida cidade como um relevante lócus de investigação. A coleta de dados deu-se por entrevistas semiestruturadas com as fundadoras desses negócios, além de pesquisa documental e em mídias sociais. Os dados foram analisados por meio de análise de conteúdo, com auxílio do software Atlas.ti.

\section{REFERENCIAL TEÓRICO}

Nesta seção são apresentados os aspectos em que se baseia esta pesquisa: cosméticos naturais artesanais, empresas verdes e suas estratégias mercadológicas e greenwashing.

\subsection{Cosméticos naturais: sustentabilidade como diferencial competitivo}

De acordo com Dilelio e Wolffenbüttel (2018), um conjunto de fatores históricos fez emergir um contexto econômico pautado por valores sociais que orientam novos modelos de produção, distribuição e consumo. Esse novo contexto abarca o conceito de economia criativa, que pode ser apresentada como um conjunto de setores e processos baseados na arte, na cultura, na criatividade, no talento e no saber vivo e cotidiano dispersos na sociedade, para gerar localmente e distribuir globalmente bens e serviços que possuam, simultaneamente, valor simbólico e econômico (Reis, 2008; Pires \& Albagli, 2012; Vega, 2021).

Apontada como uma aliada da economia verde, que busca reduzir os riscos ambientais das atividades econômicas e melhorar o bem-estar humano e social (UNCTAD, 2010; Programa das Nações Unidas para o Meio Ambiente [UNEP], 2011; Dilelio \& Wolffenbüttel, 2018), a economia criativa também almeja um desenvolvimento mais sustentável, na medida em que busca elaborar alternativas ao atual modelo econômico, que considera o meio ambiente como um mero repositório de matérias-primas (Weyermüller, Jung, Rosa \& Kehl, 2015; Kačerauskas, Streimikiene \& Bartkute, 2021).

Nesse cenário, o setor de cosméticos naturais destaca-se ao apontar para uma produção que não se utiliza de insumos e práticas que impactem negativamente o meio ambiente e a saúde das pessoas. Na condição de prática ancestral e de preservação de saberes tradicionais, a cosmetologia natural engloba princípios que vão além da estética, como saúde, bem-estar do indivíduo, comércio justo e respeito ao meio ambiente (McEachern \& McClean, 2002; Joshi \& Pawar, 2015; Serviço 
Brasileiro de Apoio às Micro e Pequenas Empresas [SEBRAE], 2016; Liobikiene \& Bernatoniene, 2017; Bernardini, Tiezzi, Laghezza Masci \& Ovidi, 2017; Lin et al., 2018; ABIHPEC, 2019a).

Combinado ao fato de que a demanda por produtos sustentáveis tem crescido, conferindo vantagem aos países com ampla biodiversidade, o Brasil possui um dos maiores mercados consumidores de cosméticos do mundo, mesmo em períodos de crise, e é detentor de uma rica biodiversidade (The Economist, 2013; Singh, Jain \& Sharma, 2015; Ashton, Russell \& Futch, 2017; ABIHPEC, 2017; Mendes, 2019), o que representa potencial para desenvolver um forte setor de cosméticos naturais no país. Além disso, o consumidor brasileiro é o que mais considera o impacto ambiental na decisão de compra relacionada a cosméticos (Organic-market, 2014).

Nesse contexto, pequenos negócios de cosmética natural de produção artesanal, típicos da economia criativa, contribuem para o crescimento do setor de cosméticos naturais no país estimado entre 5\% e 10\% até 2024 (ABIHPEC, 2019b). Como vantagem, o setor conta com a percepção do consumidor de que, quando se trata de cuidados pessoais, produtos naturais são melhores do que os seus congêneres não naturais (Kim \& Chung, 2011; Liobikiene \& Bernatoniene, 2017; Lin et al., 2018; Jog \& Singhal, 2019). A isso se soma a assimilação existente entre atributos como "delicadeza" e "sustentabilidade" e produtos de cuidados pessoais, conforme apontado por Luchs, Naylor, Irwin e Raghunathan (2010) e Vergura, Zerbini e Luceri (2020).

No entanto, o setor de cosmético natural não está imune ao fenômeno do greenwashing. Os negócios que trazem o ecologicamente correto como seu valor central, aqui chamados de empresas verdes (Pflanz, 2014), compartilham o mercado com empresas pseudoverdes e precisam lidar com um novo elemento: a desconfiança do consumidor.

\subsection{Características da empresa verde}

Segundo Perez, Garzon e Ibarra (2016), a empresa verde manifesta uma preocupação com o bem-estar e o aumento da qualidade de vida, do desenvolvimento, do progresso e do crescimento por vias distintas das atuais. Para alcançar esse perfil, as empresas têm adotado medidas como, por exemplo, atualizar campanhas publicitárias, mudar produtos, processos de produção e utilizar embalagens sustentáveis.

As empresas verdes podem ser classificadas em três categorias, segundo Pflanz (2014): a primeira abrange as empresas que têm o verde, o ecologicamente correto, como valor central do negócio; a segunda enquadra as empresas em que o verde não é o principal valor, mas os princípios verdes são integrados progressivamente nos produtos e processos da empresa; e a terceira categoria inclui as marcas em que a questão ecológica não é predominante no gerenciamento da empresa, mas a sustentabilidade é utilizada para proteger a empresa de infrações legais e os benefícios ecológicos são enfatizados em relatórios específicos sobre sustentabilidade.

Por essa ótica, uma empresa verde de primeira categoria precisa ser de alto valor para os consumidores. Também deve invocar uma resposta emocional do consumidor, e isso requer a autenticidade da marca, ou seja, sua capacidade de cumprir com os benefícios prometidos (Danciu, 2015). E, o mais importante: os princípios verdes devem estar infundidos em todos os aspectos da existência e da atividade da empresa.

Ressalte-se que, como objeto desse estudo, são pesquisados negócios verdes de primeira categoria do ramo de cosméticos naturais artesanais, integrantes da economia criativa, sendo o ecologicamente correto um valor central desses negócios (Pflanz, 2014).

\subsection{Características da empresa pseudoverde e greenwashing}

Segundo Jog e Singhal (2019), a empresa pseudoverde é aquela praticante de greenwashing, o que pode ser compreendido como "lavagem ambiental", ou seja, ações que conferem uma falsa aparência ecológica a uma empresa (Pagotto, 2013). 
O Greenpeace (2008) define o greenwashing como o ato de enganar os consumidores quanto aos benefícios ambientais de um produto ou serviço ou, ainda, às práticas ambientais de uma empresa. Assim, o greenwashing é visto como uma estratégia ilusória, pois dá ao consumidor a impressão de estar adquirindo algo virtuoso, mas, na realidade, seus méritos ecológicos são apenas aparentes (Caldas, Veiga-Neto, Guimarães, Castro \& Pereira, 2021). Empresas pseudoverdes apresentam um desempenho ambiental fraco, mas o divulgam de maneira positiva. Por não terem um desempenho que condiz com a realidade, essas divulgações podem ser percebidas como exageradas pelos consumidores, causando um comportamento de precaução e desconfiança, principalmente diante da crescente demanda por produtos orgânicos ou ecologicamente corretos (Lin et al., 2018),

O resultado disso consiste em consumidores confusos em sua intenção de compra, pois passam a duvidar dos reais benefícios de produtos e marcas ecológicas para o meio ambiente e a qualidade de vida (Jog \& Singhal, 2019; Braga, Martinez, Correa, Moura-Leite \& Silva, 2019). Nesse contexto, as empresas verdes de verdade ficam prejudicadas pelo comportamento antiético de outros atores do mercado (Pimonenko, Bilan, Horák, Starchenko \& Gajda, 2020) e precisam aplicar estratégias para se destacar e conquistar esses consumidores.

\subsection{Estratégias de marketing das empresas verdes}

As empresas verdes de verdade adotam estratégias compatíveis com a abordagem do que se conhece como marketing verde, que consiste nos esforços das organizações de criar, promover, precificar e distribuir produtos que não agridem o meio ambiente ou que são ambientalmente seguros (Bhalerao, 2015).

Para que as empresas verdes sejam consistentes no que fazem e se destaquem no mercado, Perez et al. (2016) sugerem que elas adotem as seguintes estratégias:

a) Produto: criar e comercializar produtos competitivos, verdadeiramente ecológicos, eficientes, sustentáveis e socialmente comprometidos com sua comunidade;

b) Preço: praticar um preço justo, comunicar à sociedade o motivo do sobrepreço dos produtos e descrever em que ativid ade social ou ambiental será investido esse valor;

c) Ponto de venda: assumir a corresponsabilidade da escolha dos fornecedores, dos pontos de distribuição e de venda para que não haja esquemas de especulação e depredação comercial, onde para que um ganhe, outro tenha que perder.

d) Promoção: comunicar de maneira ética e responsável, educando os consumidores sobre os atributos verdes da empresa, seus produtos e seus benefícios.

Danciu (2015) enfatiza que, para uma empresa verde ter sucesso, é necessário oferecer produtos com a qualidade, o design e o preço que os clientes esperam e concordam. Além disso, todos os argumentos ecológicos devem ser integrados em uma estratégia de comunicação que possa convencer os clientes sobre o que a compra de um produto verde traz para eles. Assim, o autor indica cinco estratégias que tendem a aumentar a preferência do consumidor pelas empresas verdes e, por consequência, fazem com que sejam bem-sucedidas:

a) Comunicação que evidencie que valores ecológicos são a essência da empresa, e não apenas publicidade. A empresa deve definir expectativas claras quanto aos seus produtos, a fim de que os consumidores não tenham margem para interpretações errôneas;

b) Relacionamento próximo com os clientes. Campanhas publicitárias devem ser honestas e inteligentes, construindo credibilidade para a empresa a ponto de não restar dúvida sobre a possibilidade de greenwashing. Ainda se devem solicitar feedbacks sobre como os clientes percebem a empresa;

c) Simplificar a comunicação com os consumidores, a fim de inspirá-los a ter atitudes ecológicas positivas, sem distorcer a complexidade das questões ecológicas. 
d) Empresas verdes devem ser positivas, envolvendo o cliente com abordagens criativas e alegres para incentivá-los a fazerem compras ecológicas;

e) Investir recursos no aumento da qualidade do produto verde para aumentar a satisfação dos consumidores e sua confiança.

Jog e Singhal (2019), por sua vez, consideram que, para que as empresas verdes se diferenciem das demais e, em especial, das pseudoverdes, elas precisam adotar as seguintes estratégias:

a) Conscientizar os consumidores sobre as práticas de greenwashing, para que não sejam enganados;

b) Dar destaque aos aspectos ambientais: as empresas verdes precisam adotar medidas ambientais adequadas e aumentar a conscientização sobre as questões ecológicas por meio de uma nova linguagem, simples e acessível.

c) Expor as empresas pseudoverdes e suas práticas enganosas: as empresas verdes precisam divulgar os comportamentos típicos de greenwashing e evidências disso. Inclusive, podem também agir de maneira conjunta e montar uma plataforma para divulgar seus esforços ecológicos e socialmente responsáveis.

d) Demonstrar o comportamento ecológico, adotando práticas sociais e ecologicamente responsáveis nos recursos humanos e em toda a cadeia de suprimentos, além de adotar os 3R's da sustentabilidade, ou seja, reduzir, reutilizar e reciclar todos os resíduos possíveis.

Assim, há uma gama de estratégias que viabilizam alternativas para que os negócios verdes do ramo dos cosméticos naturais se destaquem e obtenham um diferencial estratégico dos demais. Porém, para melhor entendimento dessas estratégias, é necessário consolidá-las de forma que se torne mais fácil sua aplicação, o que será delineado na próxima seção.

\section{MÉTODO}

Este estudo parte de uma abordagem qualitativa, descritiva e exploratória (Neergaard \& Ulhoi, 2007) e foi estruturado a partir de um estudo de casos múltiplos (Yin, 2018) que analisa três negócios do ramo de cosméticos naturais artesanais do município de Fortaleza (CE): Alquimist, Calêndula e Folha de Arruda. A escolha de Fortaleza justifica-se pelo crescente destaque que a cidade tem recebido em relação à economia criativa, tendo sido chancelada pela Unesco, em 2019, como cidade criativa do design (Prefeitura de Fortaleza, 2019), o que chancela outros setores da economia criativa, evidenciando a cidade como um relevante lócus de pesquisa.

As empresas foram selecionadas após serem observadas as características apontadas pela literatura (Pflanz, 2014; Danciu, 2015; Perez et al., 2016) que permitiram classificá-las como empresas verdes, bem como pelo fato de os casos apresentarem características inéditas, podendo servir de modelo para outras experiências. Além disso, as empresas se autodeclaram como verdes/sustentáveis, e são reconhecidas localmente por seu processo produtivo ecologicamente correto (Diário do Nordeste, 2020).

A Alquimist surgiu em 2017, a partir da proposta de sua idealizadora de unir o interesse por cosmetologia à formação na área química e produzir cosméticos que não trouxessem impactos ao meio ambiente. Assim, a marca tem produzido sabonetes, xampus e condicionadores sólidos, hidratantes, desodorantes e máscaras faciais, todos de origem vegana e biodegradáveis. A marca tem como slogan "Sustentável de verdade" e se identifica como uma empresa vegana, natural e feminista. Ainda realiza uma produção slow, que consiste em uma produção pequena, que não gera excesso de produtos e respeita o tempo de sua única produtora, a própria empreendedora.

A Calêndula surgiu em 2014, também a partir do estilo de vida de sua fundadora, que desejava reduzir o consumo de cosméticos sintéticos. Apostando na produção de sabonetes, 
hidratantes, repelentes, tônicos faciais, xampus e condicionadores sólidos, todos veganos e naturais, a marca apresenta-se como artesanal, evidenciando que seus produtos são terapêuticos e eco friendly.

A Folha de Arruda é a mais recente das três marcas, criada em 2018, a partir da vontade de sua idealizadora de tornar os cosméticos naturais produtos mais acessíveis para o público. A empresa também comercializa cosméticos naturais e sólidos (argilas, sabonetes, escalda-pés, pasta dental, xampus e condicionadores), biodegradáveis e com embalagens retornáveis.

A coleta dos dados deu-se em duas etapas: (1) pesquisa documental e pesquisa em mídias sociais (Silva \& Stabile, 2016; Severino, 2017), coletando dados secundários a partir de reportagens em veículos de comunicação local, do perfil das empresas no Instagram e de seus websites; e (2) entrevistas semiestruturadas (Gray, 2012) com as empreendedoras-artesãs responsáveis pelas marcas, realizadas em julho de 2020. Além da produção dos cosméticos, elas também são responsáveis pelas demais funções como vendas, financeiro e marketing. Elas compõem um perfil de jovens adultas com formações diversas: a idealizadora da Alquimist tem 31 anos e é formada em Tecnologia em Processos Químicos; a da Calêndula tem 33 anos e é formada em Publicidade e Propaganda; por fim, a da Folha de Arrud a tem 34 anos e é formad a em Jornalismo.

O roteiro das entrevistas foi adaptado pelos autores a partir da literatura especializada, a fim de melhor contemplar a consolidação das estratégias de marketing das empresas verdes. Ao se adotar mais de um meio para coletar dados, aposta-se na triangulação metodológica como estratégia que visa revestir a pesquisa qualitativa de maior confiabilidade e validação, além de permitir que os pesquisadores se debrucem sobre uma maior diversidade de questões, comportamentos e atitudes diante da realidade pesquisada (Bruning, Godri \& Takahashi, 2018). A análise dos dados obtidos se deu por meio da análise de conteúdo (Bardin, 2016), com auxílio do software Atlas.ti.

A partir da literatura (Danciu, 2015; Perez et al., 2016; Jog \& Singhal, 2019), realizou-se uma consolidação das estratégias de marketing das empresas verdes, chegando à estrutura apresentada na Figura 1, que constituiu as categorias para a fase de análise dos dados.

\begin{tabular}{|c|c|c|}
\hline $\begin{array}{l}\text { Aspecto do mix de } \\
\text { marketing } \\
\text { (categoria } \\
\text { norteadora) }\end{array}$ & $\begin{array}{l}\text { Categoria de } \\
\text { análise }\end{array}$ & Estratégia \\
\hline \multirow{3}{*}{ Produto } & $\begin{array}{l}\text { Criação de produto } \\
\text { sustentável }\end{array}$ & $\begin{array}{l}\text { Criar produtos verdadeiramente ecológicos, eficientes, } \\
\text { sustentáveis e socialmente comprometidos. }\end{array}$ \\
\hline & $\begin{array}{l}\text { Investimento no } \\
\text { produto sustentá vel }\end{array}$ & $\begin{array}{l}\text { Investir recursos no aumento da qualida de do produto verde e } \\
\text { do seu impacto a mbiental positivo. }\end{array}$ \\
\hline & $\begin{array}{l}\text { Adoção dos 3R's da } \\
\text { sustentabilidade }\end{array}$ & Reduzir, reutilizar e reciclar todos os resíduos possíveis. \\
\hline \multirow[b]{2}{*}{ Preço } & $\begin{array}{l}\text { Prática de preço } \\
\text { justo }\end{array}$ & $\begin{array}{l}\text { Praticar um preço justo, pelo qualos clientes esperem e com o } \\
\text { qualconcordem. }\end{array}$ \\
\hline & $\begin{array}{l}\text { Comunicação clara } \\
\text { de preço }\end{array}$ & $\begin{array}{l}\text { Comunicar à sociedade o motivo do sobrepreço dos produtos e } \\
\text { descrever em que atividade socialou ambiental será investido } \\
\text { esse valor. }\end{array}$ \\
\hline Ponto de Venda & $\begin{array}{l}\text { Escolha criteriosa } \\
\text { de parceiros }\end{array}$ & $\begin{array}{l}\text { Assumir a corresponsabilidade da escolha dos recursos } \\
\text { humanos e dos parceiros comerciais (fornecedores, dos pontos } \\
\text { de distribuição e de venda) para que não haja esquemas de } \\
\text { especulação e depredação comercial, onde para que um ganhe } \\
\text { outro tenha que perder. }\end{array}$ \\
\hline Promoção & $\begin{array}{l}\text { Comunicação } \\
\text { simples e } \\
\text { transparente }\end{array}$ & $\begin{array}{l}\text { Comunicar de maneira simples, ética, responsável, transparente } \\
\text { e convincente, de forma a educaros consumidores sobre os } \\
\text { atributos verdes da empresa, seus produtos e seus benefícios, a } \\
\text { fim de que tenham clareza do que se pode esperar da empresa e } \\
\text { de seus produtos. }\end{array}$ \\
\hline
\end{tabular}




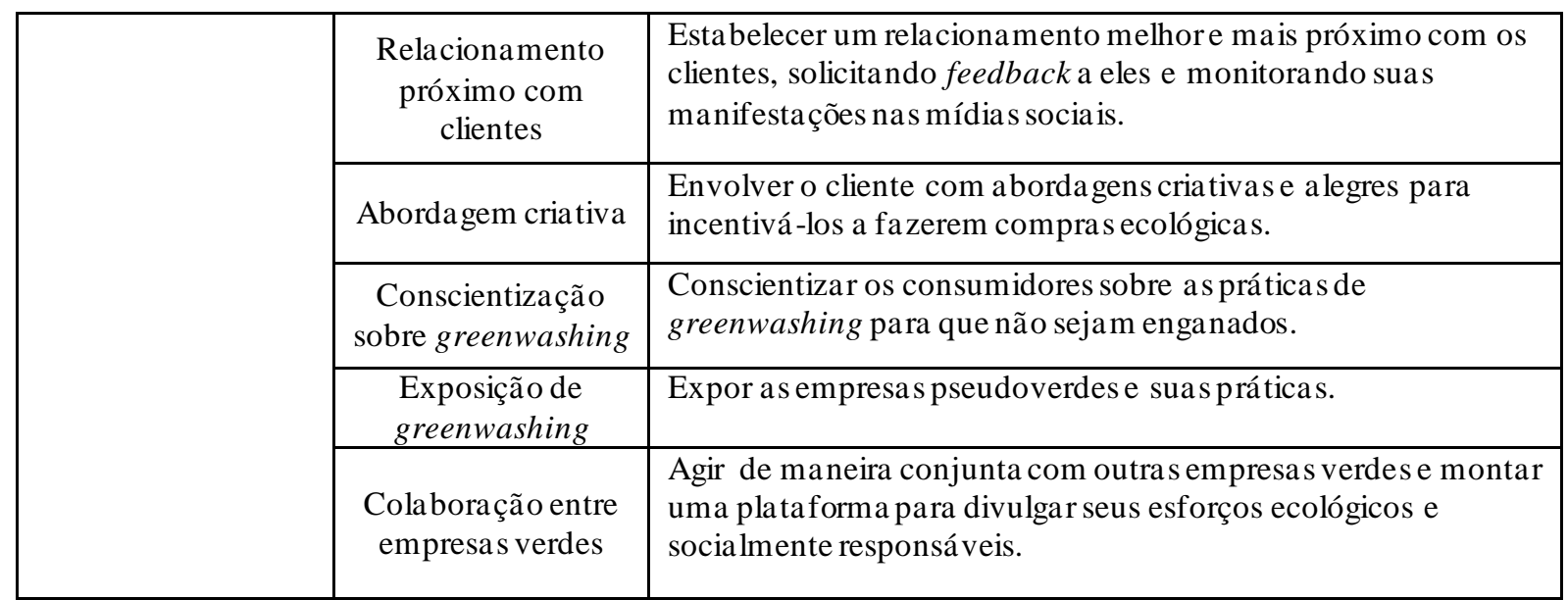

Figura 1. Estratégias de marketing das empresas verdes

Fonte: elabora do pelos autores (2020), a partir de Danciu (2015); Perez et al., (2016); e Jog e Singhal (2019)

Os resultados encontrados serão discutidos na seção a seguir.

\section{RESULTADOS E DISCUSSÕES}

A partir das entrevistas, os relatos foram categorizados e foi gerada a seguinte rede de estratégias mercadológicas (Figura 2) no software Atlas.ti.
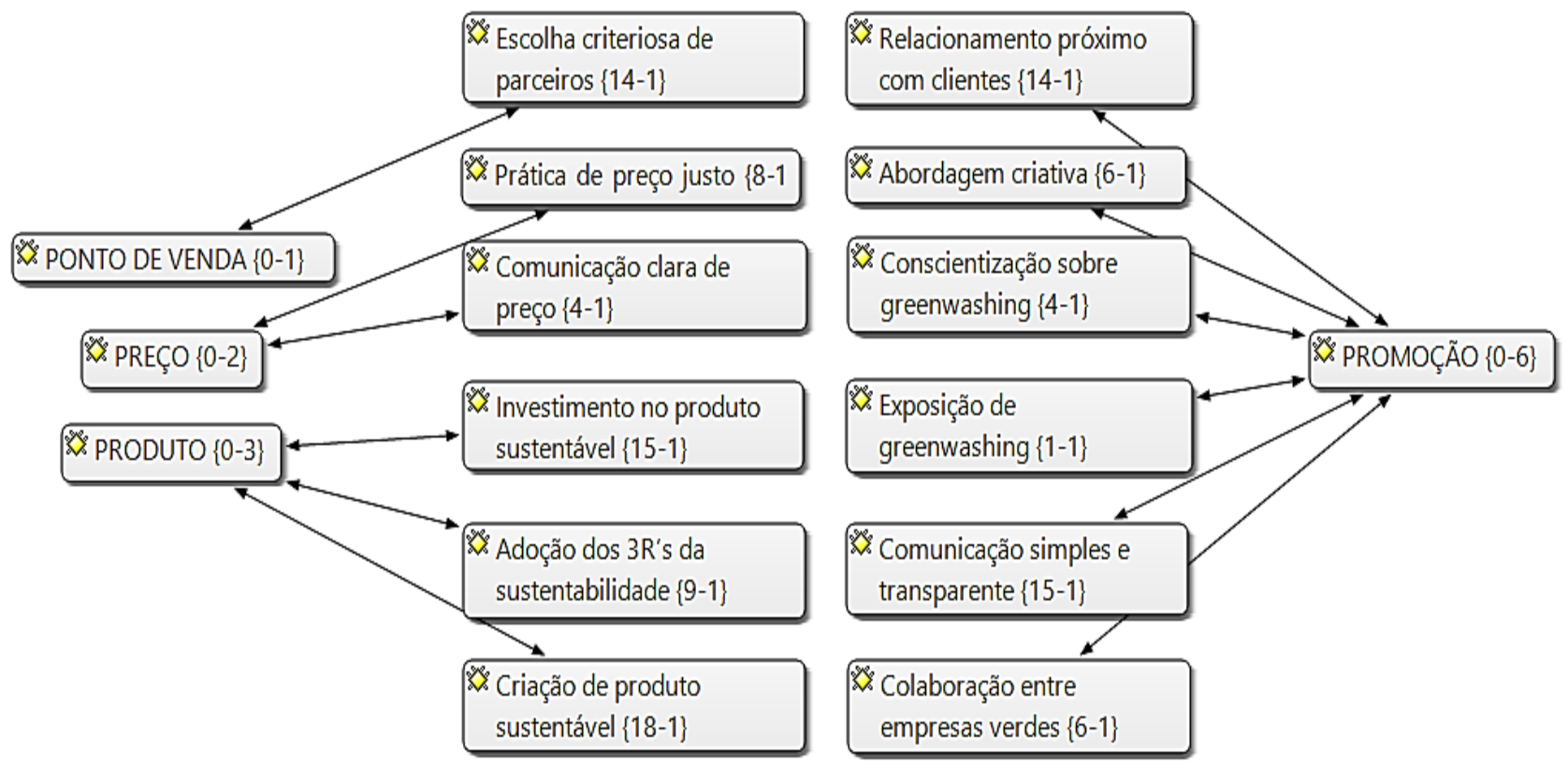

Figura 2. Rede de estratégias mercadológicas adotadas pelos negócios verdes

Fonte: Dados da pesquisa (2020)

No centro da figura estão dispostas as categorias de análise e ao seu redor se encontram os aspectos do mix de marketing do qual fazem parte. Os números dentro das chaves representam, respectivamente, a frequência com que determinada categoria foi identificada nos relatos e a quantidade de outras categorias com que esta se relaciona.

Conforme mostra a Figura 2, as estratégias relacionadas à categoria produto são as que mais se destacam, especificamente aquelas relacionadas à criação e ao investimento no produto sustentável. Em seguida, comunicação simples e transparente e relacionamento próximo com 
cliente (promoção) e escolha criteriosa de parceiros (ponto de venda) também foram estratégias apontadas de maneira recorrente nas entrevistas.

As estratégias de criação do produto sustentável, que, para Perez et al. (2016), passam pela criação de produtos competitivos, verdadeiramente ecológicos, eficientes, sustentáveis e socialmente comprometidos com uma causa da comunidade, despontam nos relatos através da preocupação com a matéria-prima, com as fórmulas utilizadas e com a embalagem dos produtos. A Alquimist, por exemplo, pesquisa a formulação de seus produtos em artigos técnicos, a fim de se certificar da segurança do que vai ser utilizado em sua elaboração, passando depois por uma fase de testes.

Quanto às matérias-primas, os negócios utilizam insumos vegetais e biodegradáveis. Ainda conforme aponta a Alquimist, a maioria das matérias-primas é acompanhada de laudos técnicos: "A gente pede o laudo técnico, inclusive laudo microbiológico, se for o caso de uma matéria-prima fresca". Mesmo os insumos que não são naturais, aqueles advindos de tecnologia verde e sintetizados em laboratório, são certificados como seguros para cosméticos naturais e devem ser biodegradáveis, conforme aponta a Folha de Arruda. Esses aspectos da criação dos produtos são bem trabalhados na comunicação dos negócios. As três marcas divulgam os insumos utilizados de forma clara nas suas redes sociais.

A criação do produto sustentável também passa pela preocupação com as embalagens utilizadas para o produto final. Os três negócios se preocupam com a redução do uso de embalagens de plástico. A criação de xampus e condicionadores sólidos, por exemplo, evita utilização de embalagens plásticas. O papel utilizado para embalar os cosméticos sólidos é biodegradável e pode ser utilizado, inclusive, em processos de compostagem.

Nesse sentido, os negócios também se mostram engajados com processos de aproveitamento dos resíduos da produção e incentivo à reciclagem ou à reutilização das embalagens de vidro e plástico por parte dos consumidores, o que vai ao encontro das estratégias de adoção dos 3R's da sustentabilidade propostas por Jog e Singhal (2019). A Calêndula, por exemplo, utiliza o Instagram da marca para dar dicas aos clientes sobre como reutilizar embalagens. Uma das estratégias utilizadas é a da logística reversa, na qual o cliente devolve os frascos dos produtos que usou, podendo ganhar descontos para compras futuras. No entanto, as entrevistad as apontam que a prática não foi incorporada pelos clientes e que o número de frascos devolvidos é muito baixo.

Quanto ao investimento no produto sustentável, os três negócios investiram recursos principalmente em capacitação. As três proprietárias, que também são as artesãs responsáveis por elaborar os produtos, realizaram cursos de cosmetologia natural com o intuito de adquirir conhecimento e habilidades para formular produtos de maior qualidade.

Alguns relatos sobre as estratégias de produto seguem na Figura 3:

\begin{tabular}{|l|l|}
\hline \multicolumn{1}{|c|}{ Estratégia } & \multicolumn{1}{c|}{ Relato } \\
\hline $\begin{array}{l}\text { Criação de } \\
\text { produto } \\
\text { sustentável }\end{array}$ & $\begin{array}{l}\text { Alquimist: "Minha produção passa pela esterilização, ainda mais a gora na pandemia [da covid- } \\
\text { 19]. [Alguns insumos] são vindos da tecnologia verde. Eles são cria dos em laboratórios, mas } \\
\text { eles têm que vir certificados. [Ainda tem] a questão da gente se preocupar com tudo, com a } \\
\text { embalagem, com a questão do social, isso ser de verdade, não ser oportunismo, sabe?". } \\
\text { Calêndula: "[Impacta positivamente] por conta da sustentabilidade, por conta de ser } \\
\text { terapêutico,por usar aromaterapia". } \\
\text { Folha de Arruda: "A fórmula básica eu aprendi nesses cursos. Mas aí a gente desenvolve } \\
\text { ingredientes específicos para aquilo que a gente quer. Então, eu elaborei essas fórmulas". }\end{array}$ \\
\hline $\begin{array}{l}\text { Investimento no } \\
\text { produto } \\
\text { sustentável }\end{array}$ & $\begin{array}{l}\text { Alquimist: "Eu fiz muito curso on-line de marketing para sustentabilidade, minha formação de } \\
\text { química e meio ambiente. Eu me matriculei na pós-graduação em cosmetologia. Eu consegui } \\
\text { mudaro plástico, eu mudeitudo para vidro". } \\
\text { Calêndula: "Fiz um curso de aromaterapia. E, atra vés da aromaterapia, eu meio que dei um } \\
\text { início. Com a tecnologia, chegou um novo produto biodegradável, que dá para a gente usar, que }\end{array}$ \\
\hline
\end{tabular}




\begin{tabular}{|l|l|}
\hline & $\begin{array}{l}\text { é compatível com o cabelo". } \\
\text { Folha de Arruda: "Eu comecei a fazer cursos tanto de saboaria quanto de cosmético natural, } \\
\text { cursos a vulsos. E, antes de fazer os cosméticos, eu estava estudando aromatera pia, então, eu } \\
\text { esperei as duas formações". }\end{array}$ \\
\hline $\begin{array}{l}\text { Adoção dos 3R's } \\
\text { da }\end{array}$ & $\begin{array}{l}\text { Alquimist: "Gera lmente, os clientes entregam [as embalagens] na loja. Se a gente for contar, } \\
\text { eu recebo menos de 10\% do que vai pro mercado. Não sei o que o povo faz, acho que joga } \\
\text { fora". } \\
\text { Calêndula: "Eu também penso nos resíduos que eu vou gerar aqui na produção. No final, tem } \\
\text { que ser biodegradável na minha marca, né? [As embalagens] são retornáveis, mas pouquíssima s } \\
\text { pessoas retornam. Pouquíssimas mesmo". } \\
\text { Folha de Arruda: "O resíduo plástico, que é o que vêm os óleos vegetais, as manteigas e tudo, } \\
\text { tem um catadorque todo sábado passa aqui. O restante não sobra muito resíduo. [...] Eu ofereço } \\
\text { desconto, dou 10\% de desconto, mas dificilmente as pessoas de volvem [as embalagens]. Aí na s } \\
\text { redes sociais eu faço um incentivo de reutilização". }\end{array}$ \\
\hline
\end{tabular}

Figura 3. Relatos de estratégias de produtos

Fonte: Dados da pesquisa (2020)

Além disso, investimentos em embalagens mais sustentáveis, em melhores insumos e na promoção dos produtos marcam as ações desses negócios, o que está alinhado ao que Danciu (2015) propõe como estratégias de investimento no produto sustentável.

No que tange às estratégias de precificação, são as estratégias de prática de preço justo que se destacam. As entrevistadas acreditam que seus produtos são comercializados a um preço justo, recebendo feedbacks dos clientes em relação a isso. Os preços praticados são calculados levando em conta o processo de produção e a mão de obra das artesãs. Os relatos da Figura 4 explicitam essas práticas:

\begin{tabular}{|l|l|}
\hline \multicolumn{1}{|c|}{ Estratégia } & \multicolumn{1}{c|}{ Relato } \\
\hline $\begin{array}{l}\text { Prática de } \\
\text { preço justo }\end{array}$ & $\begin{array}{l}\text { Alquimist: "Quando eu estou produzindo, eu cronometro o tempo que eu ga sto pra produzir até } \\
\text { embalar o produto. Aí junta hora, matéria -prima, o lucro, o quanto vai pra loja... Hoje tem uma } \\
\text { planilha, e lá já calcula tudo". } \\
\text { Calêndula: "Eu contratei, há um tempo, uma moça que ela é de marketing administrativo, não sei } \\
\text { muito bem. Ela me pediu vários dados da empresa, quanto eu investi, o meu tempo de trabalho, } \\
\text { quanto tempo eu faço com sabonete, energia, gasto fixo, enfim. Ela que fez tudo e eu só faço } \\
\text { alimentar essa planilha". } \\
\text { Folha de Arruda: "Já me disseram que os meus preços são dos mais baixos daqui do mercado de } \\
\text { cosmético natural. E não é à toa, porque eu acredito que a acessibilidade financeira ao produto é } \\
\text { muito importante". }\end{array}$ \\
\hline $\begin{array}{l}\text { Comunicação } \\
\text { clara de preço }\end{array}$ & $\begin{array}{l}\text { Alquimist: "Tenho abertura de custos na Alquimist. Mas, quando foi na pandemia, foi quando eu } \\
\text { divulguei mais, foi quando elas souberam que parte do meu valor ia [como doação para a Rede de } \\
\text { Mulheres do Maranhão]". } \\
\text { Calêndula: "Quando rola de aumentar o produto, quando está mais cara a mesma matéria-prima, } \\
\text { eu já conheço a lguns clientes, né, que voltam, aí eu sempre a viso: o preço aumentou por isso, por } \\
\text { isso e por isso". }\end{array}$ \\
\hline
\end{tabular}

\section{Figura 4. Relatos de estratégias de preço}

Fonte: Dados da pesquisa (2020)

Quanto à comunicação clara de preço, a Alquimist adota a abertura de custos, inclusive em relação às ações sociais em que o negócio atua. Esse aspecto é evidenciado por Perez et al. (2016), que defendem que as empresas verdes descrevam para a sociedade em que atividade social ou ambiental será investido o valor pago nos produtos. Quanto à Calêndula, a marca comunica quando o produto sofre um aumento de preço, explicand o aos clientes os motivos que levaram ao aumento. 
Em relação ao ponto de venda, a escolha criteriosa de parceiros é apontada como relevante entre as estratégias dos negócios em estudo. Os parceiros compreendem não somente os locais onde os produtos das marcas serão comercializados, mas também os fornecedores. Os relatos da Figura 5 sintetizam as estratégias dessa categoria:

\begin{tabular}{|l|l|}
\hline \multicolumn{1}{|c|}{ Estratégia } & \multicolumn{1}{c|}{ Relato } \\
\hline $\begin{array}{l}\text { Escolha criteriosa de } \\
\text { parceiros }\end{array}$ & $\begin{array}{l}\text { Alquimist: "O que eu sempre faço é contratar minorias. Toda vida que eu preciso [de } \\
\text { serviços como fotografia ou delivery], é sempre minorias". } \\
\text { Calêndula: "[...] E também porque ela [a loja] fica a trela da a minha marca. Os valores } \\
\text { são parecidos, o que a Calêndula acredita e o que ela acredita são [parecidos]". } \\
\text { Folha de Arruda: "Então, hoje eu vendo nesses três locais porque são pessoas que têm } \\
\text { uma linha de pensamento parecida, sabe? Com proposta de incentiv aro comércio loca 1, } \\
\text { com proposta de trabalhar com marcas sustentáveis, de falar em cosmética natural, } \\
\text { beleza natural. Quanto a os fornecedores, o que me importa mu ito é a certificação". }\end{array}$ \\
\hline
\end{tabular}

Figura 5. Relatos de estratégias de ponto de venda

Fonte: Dados da pesquisa (2020)

Conforme relatos, a escolha dos pontos de venda onde os produtos das marcas ficam disponíveis é feita levando em conta o alinhamento dos valores desses pontos de venda com os valores dos negócios. Todas as três marcas apontaram que ter uma proposta sustentável foi essencial para escolher e permanecer nos pontos de venda em que se encontravam.

Quanto à escolha dos fornecedores, as três marcas concordam com a necessidade de se verificar a certificação de quem fornece os insumos de seus produtos. Conforme aponta a Calêndula, muitas vezes esses fornecedores são indicados nos próprios cursos de cosmetologia natural que as proprietárias realizaram.

Além disso, tanto a Alquimist quanto a Folha de Arruda realizam trabalhos de apoio a alguns fornecedores. Durante a pandemia de covid-19, parte dos lucros da Alquimist foi revertida para a Rede de Mulheres do Maranhão, cooperativa que fornece o óleo de coco utilizado pela artesã em seus produtos. A Folha de Arruda, por sua vez, intensificou a compra de matéria-prima do seu fornecedor Amazônia Oil para ajudar as comunidades amazônicas que extraem os óleos para o fornecedor e que, durante a pandemia, passavam necessidade.

Além disso, as relações entre os parceiros foram apontadas como justas, não caracterizando uma relação predatória. Assim, os aspectos relatados nas estratégias de ponto de venda dos negócios estão em consonância com o que apontam Perez et al. (2016) sobre assumir a corresponsabilidade da escolha dos fornecedores, dos pontos de distribuição e de venda.

Quanto aos aspectos de promoção, destaca-se a estratégia de comunicação simples e transparente. Os negócios se utilizam principalmente do Instagram para informar aos clientes sobre fabricação e utilização correta dos produtos, inclusive no que tange ao armazenamento desses produtos. Particularmente sobre a utilização e o armazenamento, essa necessidade de comunicação se dá em razão do processo de ad aptação ao uso de cosméticos naturais, e os negócios identificaram que parte dos consumidores apresentava dúvidas sobre isso. Os negócios também comunicam sobre a composição dos produtos, seus aspectos artesanal e natural, tirando dúvida de clientes por outros canais, como aplicativos de mensagens, e apostando em um visual simples que comunique de forma direta o que precisa ser comunicado.

Analisando as redes sociais dos negócios, percebe-se o uso de imagens, acompanhado de textos contendo explicações claras, em linguagem acessível a todos os públicos, sobre os benefícios e insumos de cada produto. Também estão presentes tutoriais de utilização dos produtos, além de serem trabalhados aspectos como autocuidado, empoderamento feminino e sustentabilidade. A Alquimist também divulga suas ações sociais, esclarecendo aos consumidores de que forma parte de seu lucro é revertida para essas ações. Dessa forma, a comunicação simples e transparente desponta 
como essencial nas estratégias de mercado desses negócios, corroborando o que apontam Luchs et al. (2010) e Perez et al. (2016).

Quanto ao relacionamento próximo com clientes, destaca-se a percepção das proprietárias de que seus negócios conseguem estabelecer uma relação harmoniosa e próxima com seus consumidores. Infere-se que, pelo fato de serem pequenos negócios, nos quais a artesã também é responsável pelas vendas e pela comunicação, tais negócios conseguem estabelecer uma conexão com seus consumidores, o que passa tanto pelo recebimento de feedbacks quanto pela personalização de alguns produtos. Para Danci (2015), a construção desse relacionamento estreito é essencial, pois constrói credibilidade para o negócio verde, deixando claro para o consumidor que não há uso de técnicas de greenwashing.

A Figura 6 traz relatos representativos dessas estratégias:

\begin{tabular}{|c|c|}
\hline Estratégia & Relato \\
\hline $\begin{array}{l}\text { Comunicação } \\
\text { simples e } \\
\text { transparente }\end{array}$ & $\begin{array}{l}\text { Calêndula: "Eu sempre estou mostrando o processo de produção porque isso ajuda o cliente a } \\
\text { saber como é feito o produto. Mostraro ingrediente puro, in natura, para o cliente sabero que é } \\
\text { aquilo que a gente está botando dentro do produto. Então, eu acho que isso ajuda o cliente a } \\
\text { buscar, a querer até usar, né? Aí é naturalmesmo, né?". } \\
\text { Folha de Arruda: "[...] dá um enfoque nas imagens, que as imagens sejam objetivas, não } \\
\text { sejam imagens abstratas e tal. Você olha ali e sabe que é um xampu, e não uma coisa muito } \\
\text { artística, que você precise ler para sabero que é. A gente não faz isso aqui". }\end{array}$ \\
\hline $\begin{array}{l}\text { Relacionamento } \\
\text { próximo com } \\
\text { clientes }\end{array}$ & $\begin{array}{l}\text { Alquimist: "A maioria [dos clientes] eu conheço, eu sinto que são muito próximos. Respondo } \\
\text { cada um, eu recebo bastante [feedback], sempre positivo por direct e agora por WhatsApp, né? } \\
\text { Eu explico bem direitinho, às vezes até por áudio". } \\
\text { Calêndula: "Diariamente eu recebo feedbacks. Eles comunicam pelo Instagram, pelo } \\
\text { WhatsApp. Por onde foi feito a venda". } \\
\text { Folha de Arruda: Comigo, você pode dizer: "Eu não gostei desse teu produto por isso, por } \\
\text { isso e por isso'. Tem essa relação direta de você saber quem realmente fez o produto e você ter } \\
\text { realmente o espaço para falar". }\end{array}$ \\
\hline $\begin{array}{l}\text { Abordagem } \\
\text { criativa }\end{array}$ & $\begin{array}{l}\text { Alquimist: "[Abordagem] sincera, a legre e muito... como é que eu posso dizer? A gente ensina } \\
\text { muito, eu procuro deixar o consumidor independente. Eu tenho melhorado meu marketing, eu } \\
\text { tenho aprendido sobre isso. Eu tive que estudarmarketing digital, saber sobre aplicativos". } \\
\text { Calêndula: "No Insta gram, principalmente, a gente pode fazer uma comunicação de stories, } \\
\text { que a gente pode estar lá explicando melhor algum processo de produção. E mostraros detalhes } \\
\text { faz qua se com que a pessoa entre dentro do produto. As fotos ajudammuito a vender". }\end{array}$ \\
\hline $\begin{array}{l}\text { Conscientização } \\
\text { sobre } \\
\text { greenwashing }\end{array}$ & $\begin{array}{l}\text { Alquimist: "Eu tenho destaque só falando disso, de greenwashing, no IGTV". } \\
\text { Folha de Arruda: "Todas as cosméticas artesanais naturais fazem um serviço ma is de } \\
\text { informação e ensinam a autonomia. Você não vê [isso] em grande empresa". }\end{array}$ \\
\hline $\begin{array}{l}\text { Exposição de } \\
\text { greenwashing }\end{array}$ & $\begin{array}{l}\text { Calêndula: "Não, eu não sou militante nessa parte. Não, não faço. Fico ma is foca da na minha } \\
\text { marca mesmo". } \\
\text { Folha de Arruda: "Eu comento a respeito das práticas, sabe? Geralmente, em stories e não em } \\
\text { posts. E proponho a reflexão sobre aquilo". }\end{array}$ \\
\hline $\begin{array}{l}\text { Colaboração entre } \\
\text { empresas verdes }\end{array}$ & $\begin{array}{l}\text { Calêndula: "Existe um grupo. A gente está com planos de fazer um videozinho, mostrando a } \\
\text { força desse movimento que está nascendo, para cada uma divulgar nas suas redes, para } \\
\text { justamente já ir para o consumidor, né? Para mostrarque tem esse movimento de união". } \\
\text { Folha de Arruda: "[...] um grupo do WhatsApp de todas, a maioria, né, as mulheres que } \\
\text { produzem cosméticos artesanais aqui. Então, a gente se apoia muito, a gente troca muito } \\
\text { conteúdo. A gente critica o conteúdo uma da outra. A gente constrói o conteúdo uma da outra } \\
\text { também, sabe? A gente compra coisa em grande quantidade, a gente organiza feirinhas". }\end{array}$ \\
\hline
\end{tabular}

Figura 6. Relatos de estratégias de promoção

Fonte: Dados da pesquisa (2020) 
Sobre a estratégia de abordagem criativa, os negócios apontam que as redes sociais são aliadas nesse processo. $\mathrm{O}$ uso de ferramentas de marketing em conjunto com os recursos de redes, como o Instagram, e a utilização de vídeos e imagens que envolvam o cliente são apontados como estratégias criativas para se comunicar com os consumidores. Essa comunicação criativa e positiva é reforçada por Danciu (2015) como uma estratégia que leva o consumidor a experimentar e preferir produtos de empresas verdes.

Quanto às estratégias de colaboração entre empresas verdes, destaca-se a formação de uma rede de negócios de cosméticos naturais artesanais na cidade de Fortaleza-CE. Todos os negócios dessa rede são administrados por mulheres, apesar de isso não ser um critério para integrá-la. $\mathrm{O}$ grupo troca informações, cursos e até fórmulas de produtos. Mesmo compondo um grupo de concorrentes comerciais, elas também indicam os negócios umas das outras para clientes. De acordo com a Folha de Arruda, "em Fortaleza hoje existe um movimento", não marcas separadas. No entanto, percebe-se que essa colaboração se dá de forma diferente daquela apontada por Jog e Singhal (2019), que é mais voltada para uma ação conjunta de divulgação de esforços ecológicos e socialmente responsáveis dos negócios verdes de uma plataforma.

Em relação ao greenwashing, a Alquimist e a Folha de Arruda realizam uma comunicação que visa conscientizar o público. Esse trabalho é feito principalmente no Instagram. A Alquimist trata com frequência sobre a utilização de insumos não permitidos para produtos naturais. A Folha de Arruda tem publicações explicando o que é o greenwashing e como o consumidor pode ficar atento para não ser enganado. A Calêndula esclarece em seu Instagram que nem todo cosmético artesanal é natural, deixando o consumidor ciente sobre que aspectos deve levar em conta no momento de comprar produtos que se vendem como verdes. Tais estratégias estão alinhadas às recomendações de Jog e Singhal (2019) quanto à promoção de uma conscientização ecológica dos consumidores, fazendo-os perceberem as técnicas de greenwashing aplicadas por empresas pseudoverdes.

As estratégias relacionadas à exposição de greenwashing foram as de menor recorrência nas entrevistas. Jog e Singhal (2019) apontam que os negócios verdes precisam divulgar os comportamentos típicos de greenwashing e evidências disso. Apenas a Folha de Arruda afirmou utilizar-se de recursos da rede social Instagram para realizar a exposição direta desse tipo de prática. No entanto, como afirma a proprietária da marca, são "reflexões mais enquanto cidadã do que exatamente enquanto empresa".

\section{CONSIDERAÇÕES FINAIS}

Esta pesquisa teve como objetivo identificar as estratégias de marketing utilizadas por negócios verdes do ramo de cosmética natural artesanal, integrantes da economia criativa, para superar a desconfiança do consumidor frente às práticas de greenwashing. Verificou-se, a partir dos estudos de Danciu (2015), Perez, Garzon e Ibarra (2016) e Jog e Singhal (2019), que as estratégias mercadológicas do modelo apresentado são adotadas em diferentes níveis pelos negócios estudados.

Os negócios procuram conquistar a confiança do consumidor através da demonstração transparente do processo de produção, apresentando os insumos naturais dos seus produtos, enfatizando suas origens e propriedades, além de divulgar os benefícios ambientais e as ações de responsabilidade social atreladas às marcas, seja pela escolha criteriosa de fornecedores e pontos de venda, seja pelo engajamento em ações voluntárias em apoio a pessoas vulneráveis.

Outra estratégia utilizada é o investimento em conhecimento técnico na fabricação desses produtos, através da aromaterapia e da cosmetologia, por exemplo. Assim, assumir uma postura ética e ecologicamente responsável é uma maneira de emplacar os produtos verdes, porém isso pode não ser suficiente, devendo ser combinado com outras estratégias que envolvam investimentos e melhorias do produto verde. 
Para além do foco no produto, os negócios procuram estabelecer uma relação próxima com o cliente, o que possibilita a oferta de um serviço personalizado e informativo, de modo que os consumidores consultam diretamente as proprietárias-artesãs para sanar dúvidas sobre produtos e solicitar indicação de itens que se adéquem às suas necessidades específicas. Para esse fim, o canal mais utilizado são as redes sociais. Através dessa relação, esses negócios buscam incentivar mudanças de hábitos para que os consumidores sejam mais ecológicos, como através do retorno de embalagens. Porém, apesar do incentivo, a adesão a esse hábito ainda é baixa.

Identificou-se que a estratégia de comunicação clara de preço e do detalhamento de sua composição é pouco utilizada. Por outro lado, como os produtos estão dentro da média de preços do segmento, foi constatada a estratégia de prática de preço justo, sendo ela apontada como uma forma de promover a acessibilidade do público a produtos naturais.

Outra estratégia pouco utilizada é a exposição de práticas de greenwashing de outras empresas. Os negócios preferem enfatizar as características e os benefícios dos produtos naturais, incentivando o consumo de produtos ecologicamente corretos, diferenciando-os dos demais. O combate ao greenwashing, portanto, se dá indiretamente por meio dessas ações, porém a exposição das práticas, em específico, é raramente utilizada.

Dessa forma, nota-se que, nos negócios verdes de cosméticos naturais da economia criativa, todas as estratégias apontadas pela literatura são utilizadas, direta ou indiretamente, implicando positivamente no crescimento desses negócios. A promoção aparece como estratégia-chave para esses negócios, corroborando a literatura, pois é na divulgação dos atributos de seus produtos, da sua produção, dos valores que compartilham com os fornecedores e pontos de venda, dos preços praticados e na conscientização sobre o greenwashing que esses negócios conseguem combater a desconfiança do consumidor, construindo uma relação de confiabilidade e transparência.

Esse estudo contribui, assim, para a disseminação do modelo de estratégias mercadológicas para negócios verdes, consolidado nesta pesquisa, podendo ser replicado por outros empreendimentos que necessitam conquistar a confiança do consumidor em produtos verdes, o que pode ser considerado também um avanço teórico-empírico nos estudos que tratam do marketing de empresas verdes. Como limitação, aponta-se o fato de que o mercado de cosméticos naturais artesanais ainda não se apresenta formalmente estruturado, o que impediu a caracterização desse mercado em relação a números e tamanho. Sugerem-se estudos futuros que busquem identificar estratégias para aumento da participação do consumidor na logística reversa de embalagens, tendo em vista que se identificou baixa adesão a esse hábito benéfico ao meio ambiente.

\section{REFERÊNCIAS}

Associação Brasileira da Indústria de Higiene Pessoal, Perfumaria e Cosméticos (ABIHPEC). (2017). Essencialidade dos produtos de higiene ajuda a colocar o Brasil entre os maiores mercados do mundo. Recuperado em 19 de junho de 2020, de https://bit.ly/abihpec17.

Associação Brasileira da Indústria de Higiene Pessoal, Perfumaria e Cosméticos (ABIHPEC). (2019a). Entidades e empresas se unem em evento para apresentar soluções sobre a reciclagem do plástico. Recuperado em 19 de junho de 2020, de https://bit.ly/abijpec19a.

Associação Brasileira da Indústria de Higiene Pessoal, Perfumaria e Cosméticos (ABIHPEC). (2019b). Cosméticos verdes devem crescer 10\% nos próximos anos. Recuperado em 19 de junho de 2020, dehttps://bit.ly/abihpec19b.

Ashton, W., Russell, S. \& Futch, E. (2017). The adoption of green business practices among small US Midwestern manufacturing enterprises. Journal of Environmental Planning and Management, 60(12), 2133-2149.

\begin{tabular}{|l|l|l|l|l|l|}
\hline Rev. Gest. Soc. Ambient. & São Paulo (SP) & v.15 & p.01-17 & e02780|2021. \\
\hline
\end{tabular} 
Bardin, L. (2016). Análise de Conteúdo. São Paulo: Edições 70.

Bernardini, S., Tiezzi, A., Laghezza Masci, V. \& Ovidi, E. (2017). Natural products for human health: an historical overview of the drug discovery approaches. Natural Product Research, 32(16), 1926-1950.

Bhalerao, S. A. (2014). Green marketing: a new marketing strategy for environmentally compatible products. International Journal of Development Research, 4(8), 1757-1764.

Braga, S., Jr., Martínez, M. P., Correa, C. M., Moura-Leite, R. C. \& Silva, D. (2019). Greenwashing effect, attitudes, and beliefs in green consumption. RAUSP Management Journal, 54(2), 226-241.

Bruning, C., Godri, L., \& Takahashi, A. R. (2018). Triangulação em estudos de caso: incidência, apropriações e mal-entendidos em pesquisas da área de Administração. Administração: ensino e pesquisa, 19(2), 277-307.

Caldas, M. V. A., Veiga-Neto, A. R., Guimarães, L. G. A., Castro, A. B. C. \& Pereira, G. R. B. (2021). Greenwashing in environmental marketing strategy in the brazilian furniture market. Rev. Econ. Sociol. Rural, 59(3), 1-19.

Conferência das Nações Unidas sobre Comércio e Desenvolvimento (UNCTAD). (2010). Creative economy report: a feasible development option. New York: UNCTAD. Recuperado em 18 de junho de 2020, de https://bit.ly/unctad 10 .

Danciu, V. (2015). Successful green branding, a new shift in brand strategy: why and how it works. Romanian Economic Journal, 18(56), 47-64.

Diário do Nordeste. (2020). Xampus, condicionadores e hidratantes sólidos são alternativas de consumo sustentável. Recuperado em 09 de junho de 2020, de https://bit.ly/dne20.

Dilelio, R. C. \& Wolffenbüttel, R. F. (2018). A economia verde e criativa sob a perspectiva multidimensional: por uma sociologia econômica a partir da contribuição de Max Weber. Latitude, 12(1), 193-214.

Gray, D. E. (2012). Pesquisa no mundo real (2a. ed). Porto Alegre: Penso.

Greenpeace. (2008). Greenpeace book of greenwash. Recuperado em 17 de junho de 2020, de https://bit.ly/greenpeace08.

Guyader, H., Ottosson, M. \& Witell, L. (2017). You can't buy what you can't see: retailer practices to increase the green premium. Journal of Retailing and Consumer Services, 34,319-325.

Jog, D. \& Singhal, D. (2019). Pseudo green players and their greenwashing practices: a differentiating strategy for real green firms of personal care category. Strategic Direction, 35(12), 47.

Joshi, L.S. \& Pawar, H.A. (2015). Herbal Cosmetics and Cosmeceuticals: An Overview. Natural Products Chemistry and Research, 3(2). 
Kačerauskas, T., Streimikiene, D., \& Bartkute, R. (2021). Environmental Sustainability of Creative Economy: Evidence from a Lithuanian Case Study. Sustainability, 13(17).

Katsikeas, C.S., Leonidou, C.N. \& Zeriti, A. (2016). Eco-friendly product development strategy: antecedents, outcomes, and contingent effects. Journal of the Academy of Marketing Science, 44, $660-684$.

Kelleci, A. (2021). Four-Stage Model of Value Creation for Sustainability-Oriented Marketing: En Route to Participatory Marketing. Journal of Macromarketing, 1(7).

Kim, H. Y. \& Chung, J. (2011). Consumer purchase intention for organic personal care products. Journal of Consumer Marketing, 28(1), 40-47.

Lin, Y., Yang, S., Hanifah, H. \& Iqbal, Q. (2018). An Exploratory Study of Consumer Attitudes Toward Green Cosmetics in the UK Market. Administrative Sciences, 71(8).

Liobikiene, G. \& Bernatoniene, J. (2017). Why determinants of green purchase cannot be treated equally? The case of green cosmetics: Literature review. Journal of Cleaner Production, 162, 109120.

Luchs, M. G., Naylor, R.W., Irwin, J. R. \& Raghunathan, R. The sustainability liability: potential negative effects of ethicality on product preference. Journal of Marketing,

$74,18-31$.

McEachern, M. G.; McClean, P. (2002). Organic purchasing motivations and attitudes: are they ethical? International Journal of Consumer Studies, 26(2), 85-92.

Mendes, J. (2019). Mercado de cosméticos cresce, apesar da crise. Correio Braziliense: EconomiaRecuperado em 19 de junho de 2020, de https://bit.ly/3iJiG6H.

Neergaard, H. \& Ulhoi, J. P. (2007). Introduction: methodological variety in enterpreneurship. In H. Neergaard \&J. P.Ulhoi (Eds.), Handbook of qualitative research methods in enterpreneurship. Cheltenham, UK: Edward Elgar.

Organic-Market. (2014). Going green to access the Brazilian beauty Market. Recuperado em 19 de junho de 2020, de https://bit.ly/3m0wHyY.

Pagotto, E. L. (2013) Greenwashing: os conflitos éticos da propaganda. 2013. 162f. Dissertação (mestrado), Programa de Pós-Graduação em Mudança Social e Participação Política, Escola de Artes, Ciências e Humanidades, Universidade de São Paulo. São Paulo, Brasil.

Parguel, B., Benoît-Moreau, F. \& Larceneux, F. (2011). How sustainability ratings might deter 'greenwashing': a closer look at ethical corporate communication. Journal of Business Ethics, 102.

Perez, L.A., Garzón, M.A. \& Ibarra, A. (2016). Empresa verde: diagnóstico de la necesidad de un modelo. Dimensión Empresarial, 14(1), 57- 77.

Pflanz, S. (2014). Nachhaltige marke-die chance zur wettbewerbdifferenzierung. Idenko Markenberatung. Recuperado em 10 de junho de 2020, de https://bit.ly/31Zf1DZ. 
Pimonenko, T., Bilan, Y., Horák, J., Starchenko, L., \& Gajda, W. (2020). Green Brand of Companies and Greenwashing under Sustainable Development Goals. Sustainability, 12(4), 1679.

Pires, V. S. \& Albagli, S. (2012) Estratégias empresariais, dinâmicas informacionais e identidade de marca na economia criativa. Perspectivas em Ciência da Informação, 17(2) 109-122.

Prefeitura de Fortaleza. (2019). Fortaleza é escolhida uma das 66 cidades criativas da Unesco. Recuperado em 19 de junho de 2020, de https://bit.ly/2VT6zew.

Programa das Nações Unidas para o Meio Ambiente (UNEP). (2011). Towards a Green Economy: Pathways to Sustainable Development and Poverty Eradication - A Synthesis for Policy Makers. Recuperado em 19 de junho de 2020, de https://bit.ly/2VSQ9mG.

Reis, A. C.F. (2008). Creative economy as a development strategy: a view of developing countries. São Paulo: Itaú Cultural.

Serviço Brasileiro de Apoio às Micro e Pequenas Emrpesas (SEBRAE). (2016). Sustentabilidade: Boletim de Tendências. Recuperado em 19 de junho de 2020, de https://bit.ly/3g3ehK5.

Severino, A. J. (2017). Metodologia do trabalho científico (2a. ed.). São Paulo: Cortez.

Silva, T. \& Stabile, M. (2016). Monitoramento e pesquisa em mídias sociais: metodologias, aplicações e inovações. São Paulo: Uva Limão.

Singh, N., Jain, S. \& Sharma, P. (2014). Determinants of Proactive Environmental Management Practices in Indian Firms: An Empirical Study. Journal of Cleaner Production, 66, 469-478.

Singhal, H. \& Agrawal, A. (2021). Greenwashing: a study on consumer behaviour and effectiveness in Rajasthan. International Journal of Environmental Economics, Commerce and Educational Management, 8(2).

The Economist. (2013). Looks good. Recuperado em 19 de junho de 2020, de https://bit.ly/3g0PFlj.

Vega, J. G. (2021). The creative economy as an important industry able to encourage welfare and sustainability. International Journal of Liberal Arts and Social Science, 9(5), 31-39.

Vergura, D. T., Zerbini, C. \& Luceri, B. (2020). Consumers' attitude and purchase intention towards organic personal care products. An application of the S-O-R model. Sinergie: Italian Journal of Management, 38(1), 121-137.

Weyermüller, A. R., Jung, P. E. N., Rosa, M. E. L. \& Kehl, L. R. (2015). A indústria criativa verde e adaptação ambiental: o turismo criativo como materialização. Gestão e Desenvolvimento, 12(2), 83-96.

Yin, R. K. (2018). Case study research and applications: design and methods (6a. ed.). Los Angeles: SAGE. 